\title{
Henrique Morize e o eclipse solar total de maio de 1919
}

\author{
Henrique Morize and the Total Solar Eclipse of May 1919 \\ Antonio Augusto Passos Videira*1@ \\ ${ }^{1}$ Universidade do Estado do Rio de Janeiro, Philosophy, Rio de Janeiro, RJ, Brasil
}

\begin{abstract}
Recebido em 10 de Junho de 2019. Aceito em 11 de Agosto de 2019
Este artigo descreve o papel desempenhado por Henrique Morize na organização da expedição brasileira que foi a Sobral, no estado do Ceará, para observar o eclipse solar total de 29 de maio de 1919. Esta descrição justifica-se pela ênfase dada ao evento por Morize. Para o astrônomo brasileiro, o que realmente estava em jogo era mostrar que a sua instituição podia desempenhar tarefas científicas comuns, o que nem sempre era o caso do Observatório Nacional, uma vez que o apoio do governo federal não era regular. A fim de comprovar esta interpretação, serão usados documentos variados como cartas, artigos e declarações de Morize e colegas, em particular o relatório sobre aquele evento.
\end{abstract}

Palavras-chave: Eclipse, Brasil, ciência pura, coroa solar, observatório nacional.

This paper describes the role played by Henrique Morize in the organization of the Brazilian expedition that went to Sobral in the state of Ceará to observe the total solar eclipse of May 29, 1919. This description is justified by the emphasis given to the event by Morize himself. For the Brazilian astronomer, what really was at stake was to show that his institution could perform ordinary scientific tasks, which was not always the case with the National Observatory, since the support of the federal government was not regular. In order to support this interpretation, various documents such as letters, articles and statements from Morize and colleagues will be quoted, in particular the report on that event.

Keywords: Eclipse, Brazil, pure science, solar crown, national observatory.

\section{Introdução}

Quando considerado retrospectivamente, o eclipse solar total de 29 de maio de 1919, ou o eclipse de Sobral (CE), pode ser considerado como o ápice da carreira de astrônomo de Henrique Morize (1860-1930). Este cientista brasileiro de origem francesa já trabalhava no Observatório Astronômico do Rio de Janeiro desde 1884. Por ocasião do eclipse de Sobral, ele era o diretor dessa instituição desde 1908 ${ }^{1}$ Explicar o motivo pelo qual esse evento deve ser visto como a sua maior realização, no campo da astronomia, constitui o objetivo deste artigo.

Apesar de ser um objetivo de praticamente todos os diretores desta instituição, fundada em 1827, a Astronomia, e por razões as mais diferentes, sempre foi uma meta difícil de ser alcançada. Seja pela instalação precária, seja porque tinha que prestar serviços como determinar e fornecer a hora legal, seja por ter que compilar dados meteorológicos, o observatório astronômico tinha, até então, realizados observações astronômicas de modo irregular e sem grandes contribuições para essa área da ciência.

Assim, as efemérides astronômicas constituíam uma ocasião sempre propícia para a realização de práticas astronômicas típicas, já que as autoridades, responsá-

\footnotetext{
*Endereço de correspondência: guto@cbpf.br

1 Para outras informações sobre a vida e a carreira de Henrique Morize, ver ${ }^{[1]}$.
}

veis pela manutenção da instituição, cediam aos apelos dos seus diretores para a obtenção de orçamento extra, necessário para custear as despesas das viagens, bem como para conseguir facilidades para a organização das expedições. Em parte, as autoridades ministeriais cediam devido à publicidade que as efemérides recebiam na impressa. Afinal, não ficava bem para autoridades, que se consideravam - ou desejavam ser vistas como - civilizadas e favoráveis ao progresso cultural, negar as verbas solicitadas.

Durante a gestão de Morize à frente do observatório (1908-1929), três eventos ligados aos céus foram particularmente relevantes: a passagem em 1910 do cometa Halley e dois eclipses solares, ocorridos em 1912 e 1919. Morize foi bem-sucedido em todos os três eventos, ainda que o seu sucesso deva ser avaliado a partir de critérios diferentes entre si. Morize conseguiu superar uma série de obstáculos, que se interpuseram à sua frente, conseguindo preparar-se adequadamente para observá-los. No entanto, e por razões que serão descritas ao longo do presente texto, apenas o eclipse de 1919 pode ser entendido como tendo atingido uma realização completa. Em 1910, tal como em 1912, as condições atmosféricas impediram que as observações acontecessem como o planejado.

Em 1910 e 1912, o principal objetivo de Morize ao tomar parte em certames que despertaram curiosidade em todo o mundo era mostrar a competência científica 
da instituição que estava sob sua responsabilidade, além de contribuir para o avanço da ciência. Mas somente em 1919 pôde ele levar a bom termo esta sua intenção. Ao participar das observações do eclipse solar total de maio de 1919, Henrique Morize estava interessado em mostrar que a astronomia não era uma prática regular no observatório devido à falta de apoio externo, bem como reconstruir as suas redes de comunicação com outros observatórios, enfraquecidas devido ao conflito bélico que perdurou até novembro de 1918.

Ainda que sejam distintas, as metas que Morize procurava alcançar nessas ocasiões podem ser entendidas como representando uma exibição pública de competência científica. Contudo, o que significa esta expressão: competência científica? No seu caso, em primeiro lugar, estava em ser capaz de obter os resultados científicos planejados, mas apenas isto não seria suficiente para mostrar competência. No caso de um país atrasado em termos científicos (e não apenas!), Morize sabia que era preciso ir mais além. Competência científica, para ele, significava integrar o conjunto de países que, de forma constante e produtiva, eram capazes de se dedicar à ciência, em particular à ciência pura, ou desinteressada, aquela feita tão somente com o propósito de melhor conhecer a estrutura e o funcionamento da natureza.

Sempre que havia oportunidade, Morize, de forma objetiva, ponderada e com um tom ligeiramente didático, afirmava que o futuro das nações estava determinado pelo apoio dado à ciência pura. Ainda que a ocasião fosse outra, vale a pena prestar a atenção as palavras que proferiu em 1908, no Clube de Engenharia no Rio de Janeiro, quando o que estava em questão era a participação do Brasil em uma rede internacional dedicada à eletrotécnica. Sua mensagem era válida para todo e qualquer campo do conhecimento, aplicando-se, portanto, ao caso da astronomia:

Mas a maior vantagem, a meu ver, provirá indubitavelmente da sua cooperação intelectual a uma obra em que colaboram todas as nações cultas. Sempre me pareceu que o afastamento voluntário e quase constante do Brasil das diversas agremiações ou convenções em que se reúnem os países adiantados para promover o progresso da ciência e da indústria importa em uma espécie de suicídio intelectual, que contrasta com a sofreguidão com que outros países, entretanto, em menos favoráveis condições, buscam a oportunidade de assim manifestar sua vitalidade espiritual. ${ }^{[1]}$

\section{O início da participação brasileira no eclipse de maio de 1919: as cartas de Perrine para Morize}

O eclipse solar total de 29 de maio de 1919 entrou para a história, e não apenas da ciêncið2 ${ }^{2}$, devido à comprovação

\footnotetext{
2 O historiador Paul Johnson o considera como o início da era contemporânea.
}

de uma das previsões da teoria da relatividade geral: a luz, quando próxima a corpos suficientemente massivos, sofre uma deflexão, tal como previsto pela teoria geral da relatividade de Albert Einstein (1879-1955).

O primeiro cientista a entrar em contato com Henrique Morize com o propósito de receber informações sobre os locais de onde o eclipse poderia ser estudado foi o astrônomo norte-americano, então diretor do Observatório Nacional de Córdoba (Argentina), Charles Dillon Perrine (1867-1951). Ele já estivera no Brasil poucos anos antes, em 1912, mais precisamente em Cristina (MG), para observar outro eclipse do Sol. Naquela ocasião, como sete anos depois, o que o animava nas observações dos eclipses era verificar a hipótese einsteiniana. [2]

Em duas correspondências enviadas no primeiro semestre de 1917 (20 de abril e $1^{\circ}$ de junho), Perrine escrevia ao seu colega brasileiro:

He tenido intenciones, hace algum tempo de escribirle, sobre estaciones de observaciones para el eclipse del año 1919. Tengo esperanzas de mandar uma expedición y estaríale muy agradecido si pudiera obtener informaciones sobre los mejores lugares y los más accesibles, los que Vd haya elegido etc. Si esta guerra continua por mais tempo, el deber de observar esse eclipse restará casi por completo á los Observatorio [sic] de Sud America.

e:

Las expediciones que serán enviadas de todas las partes del mundo, si la guerra lo permite, van tener que depender de vuestro observatório, para toda clase de informaciones... [3]

A partir dessa correspondência, Morize apressou-se para conseguir as informações necessárias para a preparação das equipes. Uma vez obtidos os dados necessários, Morize redigiu um artigo - na verdade, um informe - para a revista francesa L'Astronomie, órgão oficial da Sociedade Astronômica Francesa, onde afirmava que, após análise, a sua escolha recaía sobre a cidade cearense de Sobral. Nesse seu texto, Morize mencionava o regime de chuvas, as facilidades de acesso, como também tecia comentários sobre a população local. Não se deve deixar de observar que Morize desconfiava dos locais situados em território africano. O tempo lhe daria razão: "Etant donné que les circonstances sur la côte africaine ne sont pas très favorables, un examen sérieux de ce que l'on pouvait s'attendre à trouver dans la région correspondante du Brésil s'imposaît." [4]

Morize concluía o seu informe com a afirmação de que não havia o que temer por parte das expedições estrangeiras. Sua opinião reflete o seu estado de espírito, favorável à vinda de colegas de outros países: " Le climat de la région Nord du Ceará est absolument salubre. (...) La race qui habite ce pays est douée d'une notable vitalité. (...) ... le climat est sain et qu'on ne doit pas redouter d'affronter une latitude presque équatoriale. " [4] 
Além do artigo para o periódico francês, Morize, auxiliado pelo então calculador do observatório, Lélio I. Gama (1892-1981), produziu um livreto, escrito em português, com as mesmas informações e acompanhado de um mapa do território brasileiro com a faixa de observação. ${ }^{[5]}$ As indicações de Morize foram seguidas por seus colegas britânicos e americanos. Contudo, para evitar os problemas de 1912, quando todas as expedições que vieram ao Brasil se instalaram na mesma região e que, afetadas pelas fortes chuvas que caíram, não foi possível observar o eclipse solar; os britânicos, em 1919, resolveram organizar duas expedições, uma para Sobral e a segunda para a Ilha de Príncipe, então uma possessão portuguesa. Como é hoje plenamente conhecido, a decisão dos cientistas britânicos mostrou-se acertada, uma vez que o mau tempo naquela região da costa ocidental africana impediu que as chapas fotográficas lá tiradas produzissem resultados com a robustez necessária para comprovar a relatividade geral. [6]

As organizações das expedições brasileira e britânica contêm uma série de elementos que tornam a história do eclipse de 1919 muito interessante. Se, pelo lado dos britânicos, estavam presentes fatores como o fato de Arthur S. Eddington (1882-1944) ser objetor de consciência, o que o impedia pessoalmente de ir para o front de guerra ${ }^{[2]}$, pelo lado dos brasileiros, estava em causa a vontade de superar a incompreensão das autoridades governamentais com as demandas, nem sempre vistas como normais, mas necessárias para que a equipe do Observatório Nacional pudesse chegar a tempo a Sobral para participar de um certame tão importante.

A incompreensão por parte dos dirigentes brasileiros era tamanha que ela podia chegar ao nível do ridículo, o que dava ensejo à expressão de críticas políticas, como se pode ler na notícia abaixo, publicada em 1919 na revista satírica carioca Careta:

Foi muito comentado o caso de ser preciso que o Lloyd Brasileiro adiantasse ao diretor do Observatorio Astronomico a quantia necessária para as despesas com a recepção e instalação dos scientistas estrangeiros, que vêm observar o próximo eclipse total do sol, no Ceará.

Não houve meio do Sr. Morize conseguir que o Theosouro o embolçasse do credito para esse fim votado pelo Congresso Nacional!

- Não, não era possível. As praxes burocráticas são podiam ser revogadas... O diretor do Observatorio que se arranjasse: que partisse sem o dinheiro ou esperasse...

- Como?! Tratava-se de um caso serio e urgente. Os delegados estrangeiros já se aproximavam do Ceará.... Era indispensável partir no vapor "João Alfredo", para chegar a tempo de os receber e de observar tambem o importante fenômeno...

- Mas ... em que dia se da isso? - interrogou o Director da Despeza Publica.
- A 10 [sic] de maio próximo...

- Impossivel Não há tempo! Transfira-se o eclipse para quando se anunciar...

Foi o ultimo despacho do Thesouro. D'ahi o Dr, Henrique Morize pedir a intervenção do Dr. Barboza Lima que salvou a situação declipsando os nossos créditos scientificos e cavalheirescos... ${ }^{[7]}$

A notícia acima traz uma informação interessante. Independente do 'grau de civilização' existente entre os dirigentes da burocracia brasileira, é interessante observar a complexidade da rede de contatos de Morize, que certamente usava o seu cargo de diretor do Observatório Nacional, quando a ocasião assim o exigia. Sem ajuda financeira do Llyod Brazileiro, companhia de navegação que também foi fundamental para que Morize visitasse Sobral poucos meses antes do eclipse acontecer, o destino dos astrônomos brasileiros talvez tivesse sido muito diferente.

\section{Astronomia, uma nova sede e a causa da ciência pura}

Naquele início do ano de 1919, não era apenas o eclipse solar que exigia a atenção de Morize. Outra tarefa, ou melhor, outra missão, igualmente importante, consistia em garantir a continuidade do repasse das verbas necessárias para a conclusão das novas instalações do observatório, iniciadas 6 anos antes, após um relativamente longo trabalho de escolha de sítio.

Por ocasião do lançamento da pedra fundamental da nova sede do observatório, em setembro de 1913, Morize, na presença do presidente da República, o Marechal Hermes da Fonseca (1855-1923), além de outras autoridades, aproveitou a presença do mais alto dignitário político do país para posicionar-se em favor da ciência pura. Além do valor desta última para o conhecimento em geral, ela também deveria ser incentivada pelos governantes nacionais por ser a base da chamada ciência aplicada, aquela que se mostra capaz de gerar resultados considerados úteis pela perspectiva econômica e aos quais, em geral, associava-se o progresso dos países.

Aliás, seria a causa da ciência pura que levaria Morize, juntamente com outros colegas do Rio de Janeiro, a organizar um movimento em favor da necessidade de se criar na então Capital Federal uma agremiação que os reunisse, ao mesmo tempo em que fortalecia o ambiente para a pesquisa da natureza sem outros fins que um melhor e mais verdadeiro entendimento do seu funcionamento e estrutura. A ação de Morize e colegas levou, em meados de 1916, à fundação da atual Academia Brasileira de Ciências - à época denominada Sociedade Brasileira de Sciencias. Naquele já longínquo mês de setembro de 1913, Morize iniciava o seu discurso agradecendo a presença dos governantes, mas sem deixar de vincular civilização a desenvolvimento científico: "Confesso-me imensamente grato pelo interesse manifestado por SS. Exas. em prol do 
desenvolvimento científico, que constitui o mais elevado critério pelo qual se pode apreciar o grau de civilização alcançado por uma nacionalidade."

Após o agradecimento protocolar, mas sempre obrigatório, Morize foi direto ao ponto que mais o preocupava: a ciência pura e a sua relação com o progresso de todo e qualquer país que se pretendesse alcançar o nível de civilização ou de desenvolvimento, como diríamos hoje em dia.

Estas palavras [do ex-primeiro ministro inglês Balfour ${ }^{3}$ não se aplicam somente à Inglaterra, mas a todos os países dotados de governantes previdentes e que cuidam realmente com amor de suas pátrias, não se pensando que só certos países, por serem ricos, podem ter o luxo de uma organização científica eficiente, quando é exatamente o contrário, isto é, os que são ricos, o são porque na base de sua organização se acha o saber, fonte de toda riqueza.

É forçoso confessar que estamos muito longe desse ideal, e que, por vários motivos que não posso agora estudar, o estado científico do país deixa muito a desejar, e é nosso dever auxiliar sua lenta evolução. [1]

Morize não poderia ter sido mais claro. Para ele, a verdadeira fonte de toda e qualquer riqueza é o conhecimento e não eventuais reservas minerais ou agrícolas, baseadas na qualidade do solo ou na quantidade de água disponível para o plantio. O descaso com a chamada ciência pura seria fatal, na medida em que os países, que dela se desinteressassem, estariam inapelavelmente condenados ao fracasso. Vejamos, uma vez mais, como ele se posicionou em favor da ciência:

A ciência pura, desinteressada, da qual nasceram as aplicações práticas, tal como da semente resultam a planta e o fruto, é a base da riqueza nacional, e as nações que a abandonam, fiadas no benefício provável das pesquisas feitas em países que melhor compreendem os interesses seus e da humanidade, ficarão condenadas a serem países de $2^{\mathrm{a}}$ classe, qualquer que possa ser a riqueza ostentada em certa fase. ${ }^{[1]}$

\section{A preparação para o eclipse de Sobral}

Ainda que Morize não alimentasse o objetivo de participar das observações para a comprovação do desvio da luz

\footnotetext{
3 "O êxito futuro da indústria depende das pesquisas abstratas ou científicas do presente e será aos homens de ciência que trabalham para fins puramente científicos e sem nenhum intuito de aplicação das suas doutrinas a fins utilitários que a humanidade ficará devedora nos tempos futuros. O público em geral não compreende que é aos resultados da ciência pura que devemos no passado e deveremos cada vez mais no futuro, todos os grandes progressos na prática e no saber industriais." [James Balfour]
}

pelo campo gravitacional do Sol, ele não desconhecia que tudo deveria correr muito bem em Sobral para que não se repetisse o sentimento de frustação de Passa Quatro. A sua preocupação era tamanha que, acompanhado de Domingos Costa (1880-1956), astrônomo do Observatório Nacional, visitou Sobral durante duas semanas entre os meses de março e abril de 1919.

Os objetivos dessa primeira visita eram fundamentalmente conseguir o apoio local para receber e acolher os cientistas brasileiros e estrangeiros, escolher os sítios de observação, verificar a disponibilidade de alojamento, conhecer as possibilidades de reparo para os instrumentos e, em particular, instruir a população para evitar comportamentos inadequados. A visita foi noticiada pela imprensa da região. ${ }^{[8]}$

A visita de Morize e Domingos Costa foi breve, eles não poderiam se demorar em Sobral. Era necessário regressar ao Rio de Janeiro para ultimar os preparativos para a expedição. Lançando mão do seu prestígio, Morize conseguiu o apoio do Lloyd Brasileiro, que colocou à sua disposição meios de transporte por mar. Essa deferência não escapou aos perspicazes jornalistas locais. ${ }^{[9]}$

O apoio da população de Sobral era essencial para que as observações resultassem conforme o esperado, uma vez que os sítios escolhidos estavam localizados no centro da cidade. Com o intuito de que as observações não fossem prejudicadas por um comportamento inadequado, Morize publicou um artigo em jornal da cidade explicando o que era um eclipse e como os sobralenses deveriam se comportar. Respeitando o seu estilo e a sua visão de mundo, típicos de um homem formado no século XIX, Morize recorreu à noção de civilização. Foi com as palavras abaixo que ele definiu o que seria uma atitude adequada a ser adotada pelos habitantes de Sobral:

Quanto aos homens ignorantes das regiões selvagens, produz-se entre eles verdadeiro panico. Pensam que as divindades infernaes vão destruir o deus bemfazejo do Sol, e procuram se oppor a isto fazendo toda a espécie de ruido, como o rufar de tambores, o bater de latas e o clangor das trombetas. O homem verdadeiramente civilizado, porém não comete nenhum desses absurdos. Sabe elle que se trata de um fenômeno natural, obedecendo as leis eternas traçadas pela Providencia, e cujo conhecimento habilita os homens de sciencia a prever com todas as minudencias, aquillo que parece ao vulgo, mysterioso prodígio. [9]

\section{O dia 29 de maio de 1919}

Morize, seus colegas e alguns familiares chegaram a Sobral no dia 09 de maio em trem especialmente fretado para conduzir as expedições brasileira e americana. Esta última iria estudar os efeitos do eclipse sobre os fenômenos meteorológicos e da gravidade terrestre. ${ }^{[10]}$ Os dois astrônomos britânicos já estavam na cidade. 
As três semanas até a realização do eclipse foram de trabalho intenso e febril para organizar as bases onde seriam instalados os instrumentos, para testá-los e organizar a presença dos curiosos. [8] Nesse meio tempo, Morize interagiu com as autoridades e a imprensa locais. Sendo uma autoridade competente em temas de climatologia, ele foi interrogado a respeito do clima na região, em especial sobre as causas das secas que assolavam o nordeste brasileiro. Morize afirmou que não era possível determinar com precisão as causas para esse fenômeno. Apesar de procurar falar como um cientista, Morize nem sempre era compreendido como gostaria. [11,12]

Até poucos dias antes do eclipse, o tempo mostrava-se favorável às observações. O dia 29 de maio amanheceu com pesadas nuvens no céu, o que provocou um estado de desânimo entre os observadores. [5], 13] No relatório, lido em sessão da então Sociedade Brasileira de Sciencias, e escrito para dar conhecimento ao público dos resultados obtidos em Sobral, Morize descreveu detalhadamente os instantes iniciais do eclipse. Como que procurando transmitir à audiência, que o ouvia na Escola Politécnica, onde a 22 de fevereiro de 1920, dia em que pronunciou a sua palestra, o seu estado de espírito, o cientista franco-brasileiro abandonou, por algumas linhas, o seu habitual estilo objetivo, conciso e prudente, talvez porque o considerasse insuficiente para transmitir a tensão que dominava os ares da pequena cidade cearense, atingindo cientistas e leigos:

As manhãs eram habitualmente claras, mas alguns dias antes de 29, começaram a ser encobertas por nuvens passageiras. Na manhã do dia do eclipse, essa nebulosidade se exagerou, pois todo o ceu amanheceu cerrado por K, KN e CK. As 7 h.10 m. descobre-se uma nesga azul a NE, mas ás 7 h. 40 m. o ceu novamente estava completamente cerrado. Ás 7,45 nova abertura que me permite ver, ás 7,46, pelo chercheur de meu instrumento, que o $1^{\circ}$ contacto se havia produzido. Logo depois, todo o ceu novamente se encobriu, chegando mesmo a cahir gotas d'agua ás $8 \mathrm{~h}$. $15 \mathrm{~m}$. Do lado de $\mathrm{W}$ as nuvens eram menos espessas, mas exatamente a NE, e sobre o sol, estavam pesadas massas de KN (...). Todos desesperavam, mas aos poucos esse lençol se foi adelgaçando, deixando aparecer cá e lá rasgões que, passando sobre o sol, permitiam ver que a totalidade se aproximava.

Subitamente, ás 8,42, levanta-se leve brisa de Leste que tocas as nuvens para $\mathrm{W}$, deixando ver o disco solar, já muito escurecido, no meio de larga mancha azul. Do peito de todos sahiu suspiro de profundo allivio, quando ás 8,55, de meu relógio, verifiquei ter já principiado a totalidade. Nesse momento, todos, mesmo os simples curiosos que cercavam o acampamento (...), sentiram-se comovidos pela im- ponência do espectaculo que se manifestava.

Ao final do final do eclipse, vencidas as instabilidades meteorológicas, o estado de ânimo dos cientistas era excelente, como percebido pelos jornalistas presentes, os quais informaram como tinham sido os trabalhos no dia do eclipse e o espírito dos cientistas ${ }^{[6]}$. As fotografias conseguiram ser tiradas, nem todas eram boas o suficiente, mas as que puderam ser aproveitadas, mostraram-se de muito boa qualidade. Algumas delas foram reveladas ali mesmo, em Sobral, com a ajuda de potes de barro, usados pela população local para resfriar a água. [14]

\section{O Relatório da Comissão Brasileira}

Diferentemente do que se passou com os eclipses de 1893 e 1912, que não levaram à redação e publicação de relatórios, aquele de maio de 1919 foi rico o suficiente para que Morize escrevesse um detalhado texto sobre os muitos aspectos do evento. Foram muitas as motivações que levaram à produção daquele texto, sendo possível considerá-lo ao mesmo tempo um texto de divulgação científica, uma defesa de certa concepção de ciência a pura, um relato de trabalho de campo, a descrição de observações astronômicas, a apresentação de resultados científicos obtidos e, finalmente, a descrição do funcionamento de instrumentos científicos em condições ambientais adversas. [5]

No relatório da comissão que chefiou, Morize descreve minuciosamente os problemas enfrentados pelos astrônomos. A relação dessas dificuldades, algumas superadas, outras não, era uma realidade em expedições como aquela; descrevê-los minuciosamente, ao lado das soluções encontradas, não constituía demérito algum. Ao contrário, poderia ser de alguma utilidade para outros astrônomos. Morize demorou-se, particularmente, na apresentação dos problemas com os funcionamentos das lunetas. Sobral enfrentava uma seca rigorosa na ocasião, fazendo com que a poeira entrasse pelas tendas onde estavam alojados os instrumentos, prejudicando o funcionamento, em particular, do maquinário de relojoaria.

Como já mencionado anteriormente, sempre que a situação se mostrava adequada, Morize pronunciava-se em favor da ciência pura. A apresentação pública dos resultados obtidos pelos cientistas brasileiros em sessão da Sociedade Brasileira de Sciencia foi um desses momentos:

Não é, portanto, de admirar que os modernos, embora conscientes de ser o Sol apenas um instrumento da Soberana Inteligência que governa o Universo, vejam nele importante assumpto de estudo, não somente com o fim de satisfazer nossa nobre curiosidade de conhecer as leis da natureza, mas também com o fim mais diretamente utilitário, de aumentar nosso poder sobre os agentes naturais e de melhor utilizar toda a energia que generosamente nos dá o Astro-rei. Aliás, é fato hoje 
amplamente reconhecido que toda verdade desvendada, toda lei formulada, aumentam o patrimônio da humanidade, e, passado prazo que pode ser mais ou menos longo, servem a fins de direta utilidade, que não podiam sequer ser imaginados no momento da sua descoberta. ${ }^{[5]}$

O exemplo escolhido por Morize para justificar o apoio ao conhecimento desinteressado foi extraído, como não podia deixar de ser, da própria astronomia, a descoberta do gás hélio. A qualificação de conhecimento 'pura' não devia ser entendida como absoluta ou definitiva. O desenvolvimento da ciência já tinha dado exemplos suficientes da transformação de descobertas puras em aplicações. Morize não era contrário à chamada ciência aplicada. Sua posição era de que a ciência pura deve ser apoiada e que ela é a condição de possibilidade para a existência da ciência aplicada:

O estudo do Sol e dos eclipses fornece exemplo recente desse fato que cumpro o dever de salientar. Pesquisando as protuberâncias solares no eclipse de Guntoor, na Índia, o astrônomo francês Janssen conclui de uma linha brilhante na região amarela do espectro da fotosfera, até então atribuída ao metal sódio, que esta linha não pertencia a este metal e era devida a novo corpo, que denominou hélio. (...) nos últimos meses de 1918, a Usina americana de Linde and Air Reduction já dispunha de $5.000^{3}$ de hélio, prestes a seguirem para a Europa, com o fim de encher balões militares, quando terminou a guerra. [5]

Morize começa o seu relatório, afirmando, de forma detalhada e cuidada, a importância do Sol para a vida humana sobre a superfície terrestre:

O Sol é, por tal forma o dispensador de tudo quanto ha de materialmente hom na superficie ele nossa terra, que não são demais todos os trabalhos e sacrificios feitos para melhor conhecer as leis que regem a benefica irradiação de energia que nos vem d'elle, sem a qual os planetas lhes gyrariam ao redor gelados e desertos. [5]

Após alguns parágrafos com comentários a respeito da importância do Sol como gerador de energia na Terra, Morize passa a descrever a estrutura física e química da estrela. A sua exposição cuidadosa se deve ao fato de que a coroa solar seria o 'objeto' de estudo dos astrônomos brasileiros:

Envolvendo a camada em que se manifestam as manchas, e denominada fotosfera, encontra-se outra, de espessura relativamente pequena, a qual recebeu o nome de camada inversora, por ser elle que produz por absorpção as linhas de Fraunhofer visíveis no espectro solar. Envolvendo a camada inversora existe outra mais espessa de forma extremamente variavel, que é visível apenas por occasião dos eclipses totaes, e é constituida por gazes muito leves onde predominam o hydrogeneo e o hélio, chama-se essa massa gazosa chromosphera porque durante a totalidade dos eclipses ella produz brilhantes franjas donde partem como que linguas de fogo.

Mais exteriormente ainda, observa-se a corôa vasta massa gazosa extremamente rarefeita, cuja espessura pode alcançar o comprimento do diametro do disco solar, mas que, por ser pouco luminosa, é somente visível durante a totalidade dos eclipses, apresentando então delicados matizes côr de perola. Pelas observações espectroscopicas feitas nessas occasiões, tem-se verificado existirem na coroa os elementos mais volateis, como hydrogeneo e helio, alérn de outro, ainda desconhecido na terra e chamado, devido à sua origem, coronio. Trabalhos recentes executados nos Estados Unidos, tendem a demonstrar a existencia deste ultimo, conjuntamente com o hélio, nos gazes extrahidos das fontes thermaes. [5]

A comprovação pública da competência científica da comissão brasileira somente aconteceria caso o tema de estudo escolhido despertasse o interesse de cientistas localizados em outros observatórios. Em outras palavras, a opção deveria concernir um aspecto do Sol ainda pouco conhecido pela ciência. No caso dos astrônomos brasileiros, como dito acima, a escolha recaiu sobre a coroa solar:

Até agora não foi possível observar, fóra das occasiões de eclipse total, a corôa, que ainda hoje, se conserva mysteriosa. Consiste em uma aureola, ou nimbo luminoso, que envolve o disco do Sol e da Lua, logo que este encobre o primeiro. A forma e a dimensão da corôa são extremamente variaveis e dependem muito da epoca da observação em relação á da máxima, ou da minima, das manchas, pois o cyclo é o mesmo para as duas classes de phenomenos. [5]

Fixado o interesse na coroa solar, o passo seguinte seria elaborar o programa de estudos a ser levado a cabo na cidade cearense:

Não se conhece tão pouco, com sufficiente exactidão a sua composição; de maneira que seu estudo espectroscopico é altamente recommendavel. A forma e a disposição da corôa, assim como a indagação espectroscopica de sua composição constituiram, pois, os dois principaes assumptos do programma da Commissão Brasileira em sua expedição a Sobral, 
para observar o eclipse de 29 de Maio de 1919. [5]

Morize também usou o seu relatório para descrever os objetivos e resultados das outras expedições científicas que foram a Sobral. No caso da equipe inglesa, ele se expressou da forma abaixo para apresentar a questão que interessava a Crommelin e a Davidson:

Por outro lado, o Observatorio de Greenwich, interessadissimo em elucidar a já celebre theoria da relatividade de Einstein, da qual resultam consequencias que, a serem reaes, obrigarão a introduzir profundas modificações na physica theorica e na mecanica dos corpos dotados de grande velocidade, enviou outra commissão, composta dos Snrs. Dr. A. C. D. Crommelin, notavel astronomo e mathematico e do Snr. D. Davidson, astronomo muito perito em questões de astrophysica e de photographia scientifica. A essa commissão ainda foi addido como interprete o Eng. Leocadio de Araujo, formado nos Estados Unidos. O fim principal destes Scientistas era comprovar uma das consequencias da theoria de Einstein, da qual resulta ser desviado de sua trajectoria rectilinea um raio luminoso que venha a passar perto do Sol. ${ }^{[5]}$

Morize também dedicou bastante espaço com a descrição dos instrumentos da equipe brasileira que ele dividiu em três grupos.

Grupo 1: O nosso material comprehendia os seguintes instrumentos: a) uma luneta photographica do constructor Mailhat, com $15 \mathrm{~cm}$ de abertura e $8 \mathrm{~m}$ de distancia focal, conjugada com um celostato do mesmo autor, para manter fixos os raios solares em uma direcção constante, onde se achava a luneta disposta horizontalmente.

Grupo 2: Para obviar a esse inconveniente, possuía a Comissão outro instrumento, uma pequena equatorial photographica por Steinheil de Munich, e por este reconstruída em 1912 para servir ao eclipse de Passa-Quatro, onde o mão [sic] não permitiu seu uso.

Grupo 3: A terceira parte do instrumental consistia nos espectrographos destinados a registrar a composição da coroa em diversas regiões." E "Para isto dispunha-se de um excellente espectrographo de Hilger, com a optica inteiramente de quartzo e muito transparente, portanto, para os raios ultra-violetes [sic], podendo dar 4 ou 5 espectros em placas ortho-chromaticas e anti-hale de formato de $3 \times 10$ pollegadas inglezas. Este instrumento era destinado ao estudo da luz coronal na região equatorial do Sol, proximo ao limbo. [5]
Um dos mais significativos resultados obtidos pelos colegas de Morize diz respeito a uma protuberância que apareceu na superfície do Sol. Sendo um fenômeno notável, o astrônomo brasileiro a descreveu de forma bastante rica. Além da descrição da protuberância, Morize nos informa que enviou para Perrine uma fotografia dela e que recebeu comentários muito elogiosos. O envio da imagem deve ser entendido como um gesto, não apenas de cortesia, mas principalmente como necessário para manter os vínculos científicos com o colega do Observatório de Córdoba:

As photographias com curta exposição, mostram a SE do Sol a linha da protuberancia de que já falei. A seu respeito consultei uma das maiores autoridades mundiaes em assumptos de eclipses, o Prof. Ch. D. Perrine, actual Director do Observatorio de Cordoba, na Republica Argentina, cujo governo o foi chamar no Observatorio de Lick, onde seus numerosos e notaveis trabalhos lhe tinham grangeado merecida celebridade. Enviei-lhe algumas das nossas photographias e tive a satisfação de saber que foram consideradas "esplendidas" e que a protuberancia nellas retratada era admiravel, e para citar as palavras textuaes de meu eminente collega, "the most wonderful I think in my experience" palavras que muito honram o Dr. Allyrio de Mattos a quem se devem essas placas.

A forma dessa immensa protuberancia é de um arco sahindo de um ponto do disco com $42^{\circ}$ de latitude $\mathrm{S}$, elevando-se como uma nuvem de forma complicada no meio da corôa e vindo penetrar no disco em outro ponto de latitude de $2^{\circ}$ N. A parte central do arco alcança a altura, medida angularmente da mesma maneira, de 12'. Tendo em vista que o raio do Sol é de 695.500 k m s., é muito simples calcular as dimensões correspondentes e assim acha-se que a distancia, medida no bordo do disco, entre os dois pés da protuberancia é de $515.5000 \mathrm{kms}$., e a máxima altura alcançada pelo arco, $142.700 \mathrm{kms}$. [5]

Uma vez que o cerne da preocupação da equipe brasileira estava voltado para a coroa solar, não é surpreendente que muito espaço no relatório seja dedicado à apresentação de informações sobre a sua estrutura e composição:

Pode-se, portanto admittir que a materia componente da corôa solar, com excepção da diminutissima porção que dá espectro com linhas brilhantes, se acha sob forma de particulas solidas ou liquidas muito pequenas; que a maior parte da luz proveniente da corôa interna é devida á incandescencia dessa materia, e que a da coroa externa é principalmente 
devida á luz reflectida da photosphera. Por fim, o espectro continuo da coroa interna é produzido pela elevada temperatura das particulas nella existentes.

Para corroborar esses factos e mais, si possivel, medir a velocidade de rotação da corôa ao redor do Sol, havia sido instituído o programma das observações espectrometricas, cuja installação instrumental já descrevi e que foi confiada ao zelo dos Collegas Drs. Domingos Costa e Theophilo Lee.

Antes do eclipse foram feitos os trabalhos necessarios á aferição e focalisação dos espectros sobre as placas photographicas. As observações correram regularmente durante a totalidade, tendo porém havido difficuldade em ajustar e manter as imagens do sol sobre o plano da fenda dos espectrographos por ter estado o sol completamente encoberto até dois ou tres minutos antes de começar a phase da totalidade. ${ }^{[5]}$

A última parte do relatório é constituída pela descrição dos resultados obtidos pela equipe brasileira, mas também pela equipe inglesa, o que não deixa de ser curioso. Razões para essa inclusão serão dadas mais abaixo. Quanto aos resultados de Morize e colaboradores, pode-se dizer que:

O estudo dos dois negativos restantes foi feito no Observatorio, apoz o regresso da Commissão, tendo sido medidos os espectros por diversas vezes com o comparador Hilger que possue o estabelecimento.

Embora o flint de que são feitos os prismas dos dois instrumentos seja bastante absorvente, notam-se em ambos os espectros, fortemente marca das as raias $\mathrm{H}_{\mathrm{a}} \mathrm{H}_{\mathrm{b}} \mathrm{H}$ do hydrogeneo e as do helio 5875.6 e... 4471. 5. A esse gaz tambem deve se referir a raia 4713.2 , encontrada nos dois espectros.

Com bastante dificuldade, é certo, foi possível ainda medir na placa correspondente ao instrumento B outras linhas, cujos comprimentos d'onda são:

5302.2 (também existe na segunda placa)

4685.7

4571.8

4554.1

4546.1

4532.9 Ti?

$4532.3 \mathrm{Ti}$ ?

4434.0

Destas, parece a primeira pertencer ao coronium, embora a media dos números achados para o comprimento d'onda nas duas placas diffira do valor mais recentemente adoptado, de 0,9 Angstrom.

A linha 4685.7, já observada em eclipses anteriores é tambem encontrada no espectro de diversas nebulosas. [5]

A bem da verdade, Morize não se limitou a apresentar os resultados da comissão inglesa. Ele os descreveu com algum detalhamento, ao mesmo tempo em que discorria sobre a sua relevância para a ciência. As palavras que usou nos permitem concluir que também a Morize não escapava o impacto verdadeiramente revolucionário que as concepções einsteinianas provocariam:

Resta-nos agora mencionar o importante assumpto que a Commissão Inglesa veio elucidar em Sobral. Tratava-se de comprovar uma das consequencias da theoria de Einstein, verificando si havia qualquer desvio produzido na direcção de um raio luminoso pela sua passagem proxima do sol, e, si possível, ele medir a grandeza desse deslocamento. A theoria de Einstein previa um desvio inversamente proporcional á distancia entre o raio e o centro do Sol, o qual, no caso mais favoravel para uma estrella vista tangencialmente ao disco Solar, era de 1.75, sendo na photographia apparentemente repellida a imagem da estrela perto do disco solar. A theoria de Einstein já serviu para satisfactoriamente explicar o movimento do perihelio de Mercurio, que até há pouco, era insondavel enigma, e portanto, era muito interessante ver se encontrava outra confirmação astronomica.

A Commissão Ingleza empregou para isso dois instrumentos análogos á luneta de Maihalt da Commissão Brasileira, mas com campos muito maiores e susceptiveis de abranger numerosas estrellas. Nos dois aparelhos foram registrados sete estrellas em differentes distancias do Sol. Dois mezes mais tarde em Julho, a mesma zona do centro foi novamente photographada para ter a distancia real entre as mesmas estrellas, quando sua posição não era mais perturbada pela presença do Sol. As chapas foram estudadas no Observatorio de Greenwich, cujo director, o eminente Sir [Frank] W. Dyson, teve a gentileza de me communicar o resultado das medidas, que revela completo accordo com o que a theoria de Einstein havia previsto. ${ }^{[5]}$

A passagem acima é importante para a argumentação desenvolvida ao longo deste texto, uma vez que a menção à correspondência de Dyson para Morize nos permite perceber o quão importante era para este último estar situado em uma rede de observatórios.

O último aspecto a ser salientado do relatório escrito por Morize diz respeito à característica da ciência como uma prática coletiva. 
Tendo assim rapidamente passado em revista a grande quantidade de factos agitados ou de problemas resolvidos pela observação do eclipse de 29 de Maio, não posso terminar esta palestra sem cordialmente agradecer aos meus distinctos collegas e collaboradores a pesada tarefa que tomaram sobre si, para que fosse, em circumstancias difficeis, levada a bem, a missão que nos foi confiada, e tambem ao Dr. Eug. Hime, preparador de Physica da Escola Polytechnica, a habilidade e a boa vontade com que confeccionou, pelos clichés originaes as positivas que foram projectadas para tornar menos fatigante o assumpto de que tratei. [5]

\section{Conclusão: o fim do eclipse do Observatório Nacional, a transferência da sede para São Cristóvão}

As muitas e longas passagens extraídas do relatório da comissão brasileira, escrito por Morize, foram aqui citadas para mostrar, sem deixar lugar a dúvidas, a importância que o eclipse de 1919 possuía para a equipe do Observatório Nacional. Não se tratava apenas de observar a coroa solar para melhor conhecer a sua estrutura e composição, tarefa por si só complexa e ainda relevante para a ciência astronômica.

Tão ou mais relevante do que os resultados obtidos, era provar que a expedição tinha se passado como o planejado, ou melhor, que apesar dos muitos percalços enfrentados, os astrônomos brasileiros tinham conseguido superá-los a contento. Ser capaz de conseguir das autoridades as facilidades desejadas e almejadas, escolher e transportar sem grandes danos o equipamento científico, encontrar soluções improvisadas para o melhor funcionamento de lunetas, relógios, celóstatos e espectrógrafos, adaptar-se ao ambiente, interagir com a população local e realizar as observações previstas, publicar as conclusões sobre o fenômeno escolhido, além de auxiliar as expedições estrangeiras a atingir os seus próprios objetivos, eram as tarefas a serem cumpridas. Nenhuma delas era mais importante do que outra; elas compunham uma cadeia longa, complexa e interligada.

Essa lista, quando traduzida em outros termos, significa que a observação de um fenômeno astronômico começa muito antes e termina muito tempo depois da sua ocorrência. No caso do eclipse solar total de 29 de maio de 1919, ele começou - as datas podem ser revistas - em abril de 1917, com a primeira carta de Perrine a Morize, e terminou em junho de 1920, quando foi publicado o número da Revista de Sciencias com o relatório que o astrônomo escreveu. Um fato que corrobora essa afirmação são as comunicações trocadas com Perrine e Dyson no relatório, pois elas mostram que o diálogo entre os cientistas continuou mesmo após o eclipse, agora com a troca de informações científicas provenientes das análises dos dados obtidos durante a observação do fenômeno.
Para Morize, o eclipse ainda tinha outro sentido, mais pessoal e familiar. Em 1919, ele completou 25 anos de casamento com Rosa Ribeiro Morize, a quem conheceu por ocasião de outro eclipse, em 1893. Três dias antes da célebre efeméride, Morize reuniu amigos para uma missa e para um almoço a fim de celebrar tão importante data. Nessa ocasião, o químico norte-americano, Theodor Lee, também integrante da equipe brasileira, proferiu um discurso em homenagem ao casal. Nessa ocasião, ele discorreu sobre muitas qualidades de Morize, como cientista, homem, professor e administrador científico.

Aqui, escolho citar aquelas palavras, que dizem respeito aos dons que Morize exibia como diretor do Observatório Nacional. Elas não apenas traduzem o estilo de Morize, como mostram que as dificuldades que enfrentava para exercer o seu cargo ainda hoje encontram-se entre nós:

Como administrador, Dr. Morize merece os maiores elogios. Todos nós conhecemos as dificuldades que se levantam no caminho do chefe de uma repartição técnica do Governo, dificuldades de ordem financeira - são sempre as repartições técnicas que têm de enfrentar os ataques da "economia" orçamentária, - e de ordem pessoal também, mas apesar de tudo isso, Dr. Morize tem conseguido, em fase de dificuldades que só ele poderia nos contar, manter o Observatório Nacional e até salvar, em plena guerra, as verbas necessárias à criação do novo edifício, que quando completado, habilitará o Brasil a tomar a posição no mundo científico que a sua grandeza natural impõe. Se fosse isto o seu único serviço público, ele teria pleno direito ao estilo de soberbo de Benemérito da Pátria. [15]

Realmente, a conclusão da nova sede do observatório era uma meta ansiosamente desejada por Morize. Ela significaria a concretização de um sonho acalentado por todos os diretores que o antecederam, principalmente aqueles que atuaram na velha sede do Morro do Castelo. No relatório que escreveu em 1927 a pedido do então Ministro de Agricultura, órgão ao qual estava subordinado o Observatório Nacional, Morize, ao completá-lo afirmava:

Quem viu, e isto é quase de ontem, o triste espetáculo de uma repartição científica em que o Diretor se assentava e recebia visitas de notabilidades em seu gabinete, sob um toldo de lona, para evitar que se reproduzissem as inundações que, por mais de uma vez, inutilizaram os papéis oficiais e os livros de sua biblioteca, não pode deixar de sentir séria emoção à vista do atual edifício e do esplêndido material que guarnece e habilita aqueles que me vão suceder e, por seu trabalho inteligente e contínuo, grangear justo renome ao Observatório Nacional, cuja reputação virá recair sobre nosso querido Brasil..[16] 
Se, por um lado, é correto afirmar que a transferência para o Morro de São Januário, localizado no bairro carioca de São Cristóvão, era um evento, por si só, histórico, por outro, ele não exibia, ou, ao menos, não deixava aparecer com total resplandecência, aquela faceta que Morize gostaria de mostrar aos seus colegas cientistas. Ainda que tivesse realizado outras tarefas científicas, Morize sentia que lhe faltava ser reconhecido como astrônomo. O eclipse de Sobral permitiu que, finalmente, tal reconhecimento se tornasse público. Em carta de 24 de novembro de 1919, o astrônomo real Frank W. Dyson (1868-1939), enviada para agradecer em nome dos colegas britânicos o empenho de Morize, ele assim se expressou:

From my own experiences of Eclipse Expeditions, I know the difficulties, and understand to what a large extent success in dependent on the good will and voluntary assistance accorded to the observers. In Brazil they lacked nothing, and this is mainly due to the excellent way in which you, as an Astronomer, were able to carry into effect the generous provision of the Brazilian Government. ${ }^{[3]}$

Em uma época em que a ciência no Brasil ainda era frágil e sem poder contar com o apoio necessário e merecido, as palavras de Dyson coroavam uma vida exemplar, completamente dedicada à causa do conhecimento.

\section{Agradecimentos}

$\mathrm{O}$ autor agradece o apoio do $\mathrm{CNPq}$ através de uma bolsa de produtividade em pesquisa (processo $n^{\circ} 306.612 / 2018$ 6) e à Faperj por uma bolsa Prociência.

\section{Referências}

[1] A.A.P. Videira, Henrique Morize e o ideal de ciência pura na República Velha (FGV, Rio de Janeiro, 2003).

[2] I.C. Moreira e A.A.P. Videira, em: A Relatividade Geral Verificada: o eclipse de 29/05/1919 (UFRJ, Rio de Janeiro, 1995), v. 1, p. 77-99

[3] Museu de Astronomia e Ciências Afins, Eclipse de Sobral. 100 anos, disponível em http://www.mast.br/sobral/ img-documentacao.html, acessado em 31/05/2019.

[4] H. Morize, L'Astronomie 33, 49 (1919).

[5] Henrique Morize, organizado por A.A.P. Videira (Fundação Miguel de Cervantes, Rio de Janeiro, 2012).

[6] L.C.B. Crispino e D.J. Kennefick, Nature Physics 15, 416 (2019).

[7] http://omalho.casaruibarbosa.gov.br/revista. asp?rev $=867$ \&ano $=1919$

[8] Dr. Henrique Morize, Folha do Litoral, 9 de março de 1919.

[9] Dr. Henrique Morize, Folha do Litoral, 16 de março de 1919.

[10] L.C.B. Crispino e M.C. Lima. Revista Brasileira de Ensino de Física 40, e1601 (2018).

[11] Dr. Morize e a Secca, Folha do Litoral, 20 de abril de 1919.
[12] R.R.F. Mourão, Einstein: De Sobral para o Mundo (UVA, Sobral, 2003).

[13] De Sobral - O Eclypse do dia 29 (Do correspondente), Folha do Litoral, 8 de junho de 1919.

[14] J.M. Rodrigues, Entre Telescópios e Potes de Barro. Expedições Científicas do Eclipse Solar na Comprovação da Teoria da Relatividade em Sobral - CE/1919. (Appris Editora, Curitiba, 2019).

[15] T. Lee, em: Einstein. De Sobral para o Mundo (UVA, Sobral, 2003), p. 157.

[16] H. Morize, Observatório Astronômico: Um século de história (1827-1927) (Salamandra/MAST, Rio de Janeiro, 1987), p. 179 . 